\title{
The Beast, the Borg, and the Role of the EMR
}

\author{
Benjamin R. Doolittle, MD, MDIV'] and Patrick G. O'Connor, MD, MPH²
}

'Departments of Internal Medicine (General Medicine) and Pediatrics, Yale University Medical School, New Haven, CT, USA; ${ }^{2}$ Department of Internal Medicine (General Medicine), Yale University Medical School, New Haven, CT, USA.

J Gen Intern Med 35(8):2447-8

DOI: $10.1007 / \mathrm{s} 11606-019-05474-w$

(C) Society of General Internal Medicine 2019

I n 1996, the Star Trek movie First Contact was released. The movie describes the Borg, a computer-organic entity that sails through the universe conquering other life forms and assimilating them into the collective. All conscious creatures are absorbed into a shared consciousness whose purpose is to dominate other civilizations. Their tag line is, "Resistance is futile." The swarthy Captain Jean-Luc Picard is the only one who has ever escaped the Borg. His freedom is costly. He is haunted by nightmares and flashbacks. Only through a Hollywood ending — "Fire photon torpedoes!" - is the Borg defeated.

But was the Borg really defeated? Consider this, the electronic health record (EHR) is often cited as an important source of physician burnout, reduced patient satisfaction, and equivocal quality indices. ${ }^{1,2}$ On the wards, our Workstation on Wheels (WOW) functions almost like a person. It is about the height of a person, and travels with us from room to room. The WOW will often have a coffee cup perched on its table, like many of us have in hand. We consult this entity regularly about lab and $\mathrm{x}$-ray results and even use it to answer clinical questions. The WOW is a member of the team.

In clinic, when I log onto our EHR, I am confronted with a screen that reports the time it takes me to return phone calls and complete notes. Is this what my clinical activity amounts to? It seems that, instead of the computer serving me, I am the one who serves the computer. I am no Luddite. I can fully appreciate the power of the computer to save lives and improve efficiency. I remember the exasperation when a paper medical record went missing, the impossibility of finding the MRI result amidst the ragged papers, the consult note that disappeared. How did we care for patients before computers?

There is a deeper question, one introduced by the Star Trek movie. How does the EHR re-define our humanity? Have we physicians lost our souls to the great collective Borg-EHR? Over the centuries, we have asked similar questions. In Plato's

Received September 11, 2019

Revised September 11, 2019

Accepted October 9, 2019

Published online November 8, 2019
Republic, he asked, "Are we gods or beasts?" His conclusion was as follows: we are neither gods because we are mortal nor are we beasts because we exercise reason and congregate in cities. We are something altogether different: we are human. The challenge was not whether we would be consumed by the Borg, but would we be lost to our animal instincts. Plato claimed that we are more than beasts, not unlike how we claim to be more than the Borg.

The question of our humanity captured our imagination during the Renaissance. Perhaps our fundamental question could have been, "Are we bodies?" The Renaissance was when we rediscovered the human form. Painters took the clothes off their subjects. Vesalius began human dissections in the University of Padua, carefully recording his findings and subverting Galen's outdated anatomy. In 1543, he published his celebrated De humani corporis fabrica (On the making of the human body) which featured anatomical drawings with dramatic renaissance flare (Fig. 1). ${ }^{3}$ We were bodies, but somehow more-beautiful, animated, poised.

The question of our humanity amidst modernity plagued us again during the nineteenth century Industrial Revolution. "Are we machines?" With the advent of the steam engine, we left our villages and flocked to the cities for the factory jobs. We became assimilated into machines. Children were preferred to adults with their nimble fingers and smaller size. But these were not always happy times. Urban life was often anonymous and harsh - think Dickens' Oliver Twist or Hugo's Les Miserables. Children were objectified and victimized. Progress was pursued at the expense of the environment and community. Claude Monet's painting Sunrise captures this forlorn sentiment (Fig. 2). ${ }^{4}$ There is the lone figure in the harbor. Any identifying detail is obscured by the mist of sunrise (or is it smog?). In the background loom smoke stacks and ships' rigging. The figure appears overwhelmed by the blue smog, the lurking mysterious shapes in the background. Is the figure trying to escape? Simply adrift? We are only left to imagine.

Joseph Licklider, a psychologist by training, became a visionary computer scientist during the early years. In 1960, he published a paper, "Man-computer symbiosis," where he wrote, "The hope is that ... human brains and computing machines will be coupled together very tightly and that the resulting partnership will think as no human has ever thought and process data in a way not approached by the informationhandling machines we know today." "From this paper, we encounter the question of our age, "Are we computers?" 


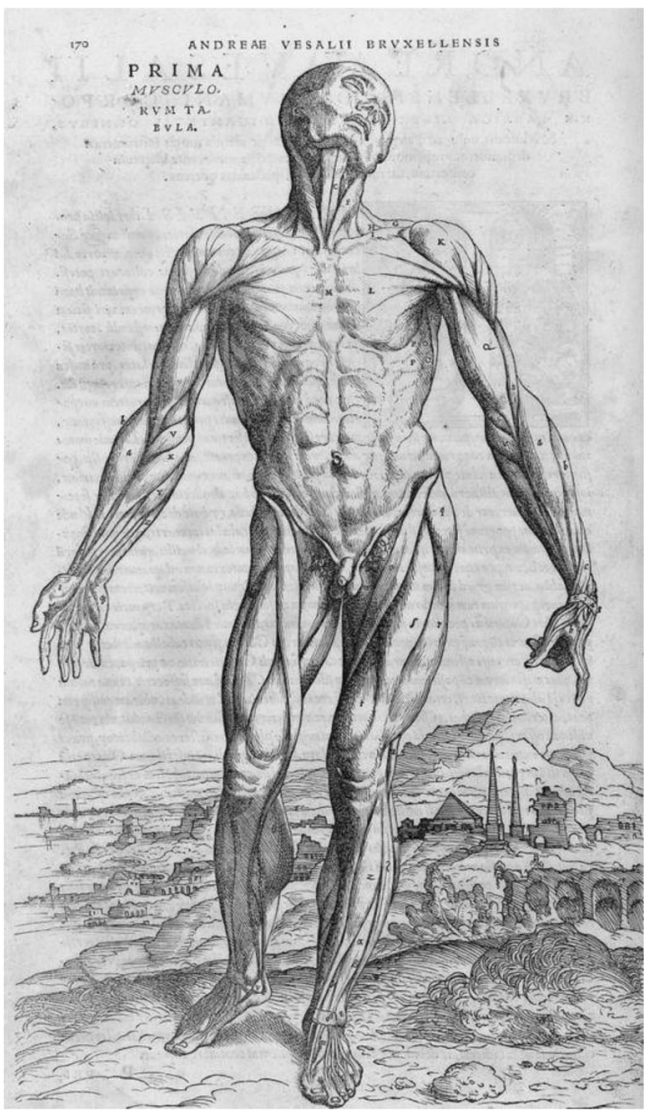

Fig. 1 Anatomic drawing from Vesalius' De humani corporis fabrica.

Licklider was quite optimistic in his view that humans and computers would exist in symbiosis, with a great benefit to humanity. He takes a positive spin to the Borg.

I believe we are in the era of EHR 1.0. We serve the computer, rather than the computer helping us serve the patient. We are in desperate need for EHR 2.0, when computers

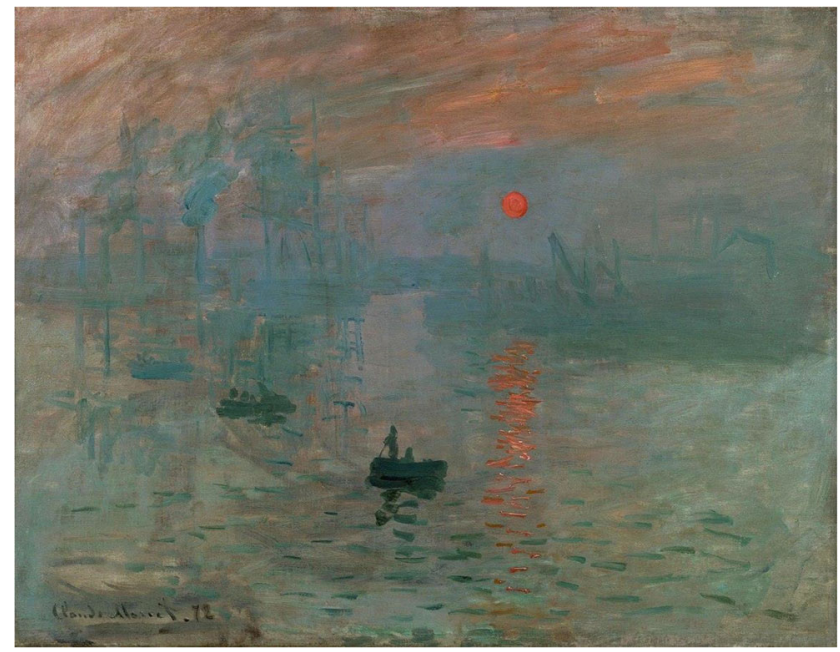

Fig. 2 Claude Monet's Sunrise. allow me to spend more time with patients rather than less. The first iteration of the Internet was about information. We would access information on static web pages - the weather, news, stock prices, movie times. Internet 2.0 is about connectivity and relationship. Facebook, Twitter, Instagram, and the rest are all about keeping us connected - sometimes to excess.

What would an EHR 2.0 look like to make my care more caring? Those wiser than I have awakened to this question. The American Medical Informatics Association (AMIA) has put out a position paper which highlights five domains: (a) simplify and speed documentation to reduce the burden on physicians, (b) refocus regulation to make it more efficient to record meaningful use metrics, (c) increase transparency and streamline certification, (d) foster innovation, (e) and support person-centered care delivery where pharmacies, home health agencies, physical therapists, and the like are integrated into the same system. ${ }^{6}$ They are the experts. Will this be enough?

My own sense is that the question of our humanity amidst modernity will persist with inherent tension. The tools of our progress are the tools by which we redefine ourselves. Do we enjoy the fruits of our industry or are we lost in the smog like Monet's Sunrise? The Borg is here. Is resistance really futile? Or, is there a future where the EHR makes our care more caring?

Corresponding Author: Benjamin R. Doolittle, MD, MDIV; Departments of Internal Medicine (General Medicine) and Pediatrics, Yale University Medical School, New Haven, CT, USA (e-mail: Benjamin. doolittle@yale.edu).

\section{Compliance with Ethical Standards:}

Conflict of Interest: The authors declare that they do not have a conflict of interest.

\section{REFERENCES}

1. Shanafelt TD, Dyrbye LN, Sinsky C, Hasan O, Satele D, Sloan J, et al. Relationship between clerical burden and characteristics of the electronic environment with physician burnout and professional satisfaction. In Mayo Clinic Proceedings 2016;91(7):836-848.

2. Babbott S, Manwell LB, Brown R, Montague E, Williams E, Schwartz M, Hess E, Linzer M. Electronic medical records and physician stress in primary care: results from the MEMO Study. Journal of the American Medical Informatics Association. 2013 Sep 4;21(e1):e100-6.

3. Vesalius A. https://en.wikipedia.org/wiki/Andreas_Vesalius\#/media/ File:De humani_corporis fabrica (27).jpg. accessed on July 27th, 2019.

4. Monet C. https://en.wikipedia.org/wiki/Impression,_Sunrise\#/media/ File:Monet__Impression,_Sunrise.jpg. accessed July 27th, 2019.

5. Licklider JC. Man-computer symbiosis. IRE transactions on human factors in electronics. 1960;1:4-11.

6. Payne TH, Corley S, Cullen TA, Gandi TA, Harrington L, Kuperman GJ, et al. Report of the AMIA 2020 Task Force on the status and future of EMRs. J Am Med Inform Assoc. 2015;0:1-11. doi:https://doi.org/10. 1093/jamia/ocv066.

Publisher's Note Springer Nature remains neutral with regard to jurisdictional claims in published maps and institutional affiliations. 